\title{
Efecto del tratamiento al vacío en pulpas de manzana, durazno, mango y fresa mínimamente procesadas
}

Effect of vacuum treatment on minimally processed apple, durazano, mango and strawberry pulpes

${ }^{1}$ Ángel N. Quispe Talla ${ }^{a},{ }^{1}$ Nelly R. Castro Vicente ${ }^{a}$

\section{RESUMEN}

El consumo de alimentos mínimamente procesados, principalmente frutas troceadas empacadas, ha aumentado considerablemente en los países desarrollados. Los tratamientos más comunes de los productos mínimamente procesados son pelado, troceado, o facilitadores del proceso mediante la eliminación del aire y propiamente el oxigeno; lo que permite la prolongación del tiempo de vida útil de estas pulpas propiciando pequeños cambios composicionales que ayudan a alargar su vida útil porque el índice respiratorio se ve influenciado por las soluciones isotónicas en las frutas ya que ocupan el espacio dejado por el aire. El estudio ha analizado la eliminación del aire con una presión de vacío de 50 mbares en un tiempo de 10 minutos permitiendo el ingreso de soluciones isotónicas de glucosa de 14 y 17 grados Brix prolongando el tiempo de vida útil hasta 20 días en temperatura ambiente; solo la fresa presento una pérdida de sus pigmentos enturbiando la solución de cubierta de las frutas mínimamente procesadas sin uso de calor para su conservación

Palabras clave: Vida útil, Solución isotónica, tratamiento al vacío.

\begin{abstract}
The consumption of minimally processed foods, mainly fruits cut and packaged, has risen sharply in developed countries. The most common treatments for minimally processed products are peeled, cut, or facilitators of the process by eliminating the actual air and oxygen, thus allowing the extended lifespan of these pulps promoting small compositional changes that help to extend their life because the respiratory rate is influenced by isotonic solutions in fruits because they occupy the space left by the air. The study investigated the removal of air with a vacuum pressure of 50 mbar in a time of 10 minutes allowing the entry of glucose isotonic solutions of 14 and 17 degrees Brix prolonging the shelf life up to 20 days at room temperature only Strawberry present a loss of pigment solution clouding cover minimally processed fruits without use of heat for their conservation.
\end{abstract}

Keywords: Shelf Life, Isotonic solution, vacuum treatment

\footnotetext{
${ }^{1}$ Universidad Nacional Santiago Antunez de Mayolo

${ }^{\mathrm{a}}$ Ingeniero Industrias Alimentarias
} 


\section{INTRODUCCIÓN}

En la actualidad la tendencia del consumidor es comer sano y variado incrementándose el consumo de los productos de cuarta y quinta gama y los productos con mínimo procesamiento no escapan a este consumo.

En el callejón de Huaylas la mayoría de las frutas y hortalizas están siendo comercializadas sin el mínimo de higienización, presentándose al consumidor con mucha carga de gérmenes viables e incluso con muchos patógenos que producen daño al consumidor y por ende disminuyen su calidad comercial.

El consumo de alimentos mínimamente procesados, principalmente frutas $\mathrm{y}$ hortalizas troceadas y empacadas, ha aumentado considerablemente en la población urbana, los tratamientos más comunes de los productos mínimamente procesados son pelado, troceado, $\mathrm{y}$, en algunos casos, fortificación con componentes nutricionales o facilitadores del proceso; es así como la respiración condiciona la vida útil tanto de los vegetales enteros como de los mínimamente procesados; 1 a concentración de gases de la atmósfera, la temperatura y otras variables pueden alterar el fenómeno de la respiración.

La generación de vacío en los empaques es uno de los tratamientos que se les puede aplicar a las frutas mínimamente procesadas para disminuir los niveles de O2, así como para introducir en la estructura: antioxidantes, conservantes, azúcares, ácidos. Gracias a la estructura porosa que ofrecen las frutas y que propicia pequeños cambios composicionales que ayudan a alargar su vida útil. El índice respiratorio influenciado por la generación de vacío con soluciones isotónicas en las frutas, se considera una tecnología que favorece la vida media de las frutas.

La preservación de las frutas por medio de la modificación de la atmósfera que los rodea ha demostrado ser una buena alternativa y complemento a los procesos de conservación de frutas mínimamente procesadas con la adición de la refrigeración, y teniendo en cuenta los sistemas de los laboratorios especializados de la facultad que cuentan con una línea de mínimo procesamiento así como los sistemas de empacado al vacío, los resultados de estas técnicas permitirán generar un paquete tecnológico para los procesos de producción estandarizada que los laboratorios especializados de la facultad de ingeniería de alimentos de la Universidad Santiago Antúnez de Mayolo necesita.

Las consideraciones anteriores permiten que el presente trabajo sea una alternativa nueva de conservación; para cumplir el objetivo general de Prolongar la vida útil de las frutas mínimamente procesadas con la generación de vacío en los empaques con soluciones isotónicas; y los objetivos específicos siguientes:

- Determinar las concentraciones 
óptimas de soluciones isotónicas para el envasado al vacío de pulpas de manzana, durazno, mango y fresa.

- Determinar el efecto de vacío en la conservación de pulpas de frutas mediante el uso de soluciones isotónicas de glucosa después de la eliminación del aire.

\section{Tecnología de Barreras}

Las barreras son parámetros físicos o químicos que se pueden ajustar para asegurar la estabilidad microbiana y seguridad de los alimentos. Los parámetros físicos incluyen temperaturas de procesado y almacenamiento, actividad de agua, $\mathrm{pH}$, potencial redox del alimento, y conservantes utilizados en los microorganismos y ello da lugar a un alimento seguro. Barbosa G, Usha P, Palau E, Swanson B (2000).

La tecnología el alimento. Los parámetros están controlados a niveles que inhiben o inactivan de barreras se utiliza en la conservación de carne y frutas hortalizas estacionales o regionales. Barbosa G, Usha P, Palau E, Swanson B ( 2000 ).

Las barreras químicas y bioquímicas incluyen antimicrobianos, antioxidantes, humectantes, secuestrantes y bactericidas. Los antimicrobianos pueden estar presentes en los alimentos de forma natural, formados como respuesta a un esfuerzo o añadidos con el propósito para la conservación. Enzimas tales como la lactoperoxidasa, proteínas tales como caseína y lactoferrina, o pigmentos tales como antocianos presentes en los alimentos poseen propiedades antimicrobianas. Ácidos orgánicos como cítrico, málico, sórbico, tartánco, propiónico y benzoico son acidulantes potenciales añadidos a los alimentos para prolongar su vida comercial. Wills RH, Lee TH, McGlasson ( 1984).

Los bactericidas son moléculas que contienen proteínas con la capacidad de inhibir los patógenos del alimento. Las colicinas producidas por Escherichia coli y la usina producida por la bacteria de ácido láctico son bactericidas producidos de forma natural. P. Muriana ( 1992).

La nisina se utiliza para inhibir la saturación por gas causada por Clostridiun, en queso y en la formación de esporas de bacterias gram positivas, gram negativas y levaduras en quesos untables, hortalizas enlatadas, sopas y budín. La adición de nisina a los batidos de chocolate y leche evaporada reduce el tiempo de procesado térmico. M.A. Daeschel (1989).

Cada una de las tecnologías no térmicas tiene aplicaciones específicas en términos de los tipos de alimentos que pueden ser procesados. Por ejemplo, la alta presión, los campos magnéticos oscilantes, los antimicrobianos, los pulglasos lumínicos y la tecnología de barreras se pueden utilizar tanto en alimentos líquidos como sólidos, mientras que los campos eléctricos pulsados es más fácil aplicarlos 
en alimentos líquidos y la irradiación es eficaz para alimentos sólidos. Asimismo, los pulsos lumínicos son más eficaces para la pasteurización de superficies. Además, los pulsos lumínicos, la irradiación y los campos maglanéticos se pueden utilizar para procesar alimentos preenvasados, reduciendo el riesgo de contaminación por contacto o postprocesado. Por tanto, las tecnologias no térmicas no se pueden aplicar al procesado de toda clase de alimentos. Cada tecnología no térmica posee sus ventajas y limitaciones. En algunos casos, por ejemplo, en la inactivación de esporas es necesario utilizar un planteamiento de métodos combinados. Barbosa G, Usha P, Palau E, Swanson B (2000).

Aunque estudios preliminares indican resultados prometedores, pasará cierto tiempo hasta que las tecnologías no térmicas se puedan utilizar a escala comercial. La mayoría de las investigaciones se enfocan en aplicaciones para tecnologías no térmicas, y unas pocas en comprender los mecanismos de inactivación de microorganismos, esporas o enzimas. Los cambios ultraestructurales en células de Saccharomyces cerevisiae, E. coli y Staphylococcus aureus tratados en campos eléctricos pulsados y en células de S. cerevisiae tratadas con alta presión fueron observados utilizando microscopia electrónica en un intento de comprender los mecanismos de inactivación. El tratamiento con camp s eléctricos de células de S. cerevisiae y S. aureus dio como resultado la ruptura de la membrana celular. Obviamente, la membrana celular de E. cotí no fue dañada por el campo eléctrico. Al aplicar un tratamiento de alta presión en células de $\mathrm{S}$. cerevisiae se produjo una ruptura de la membrana. Estos estudios indican que la membrana celular queda dañada o se produce una ruptura que puede o no ser el mecanismo primario de la inactivación. Por tanto, son necesarios nuevos estudios para encontrar los mecanismos de inactivación. Con una adecuada comprensión de los mecanismos de inactivación de las tecnologías no térmicas algunas de las limitaciones pueden potencialmente ser superadas o donde una tecnología falla, se pueden utilizar otras Barbosa G, Usha P, Palau E, Swanson B (2000).

\section{FRUTAS}

Es el producto comestible de una planta y está constituido por la semilla y su envoltura la cual puede ser pulposa, jugosa o seca. La definición botánica de fruta, es el producto del crecimiento de una flor, inflorescencia, angiosperma.

Las frutas poseen un sabor y aroma intensos que pueden consumirse en crudo, cocidos, o en conserva. Son alimentos muy perecederos AGL (2 001) y CEBAS (2008).

\section{Características nutricionales de frutas}

Según Benitez, et al. ( 1 999), reportan que las frutas:

- Presentan un alto contenido de 
- frecuentemente como azúcares mono y disacáridos (glucosa, fructosa y sacarosa) que le confieren dulzor a las frutas. Cuanto más maduras son, mayor concentración de azúcares tienen.

- Contienen importante aporte vitamínico (vitaminas A, C, B1, B2, B6, ácido fólico) y mineral (potasio, hierro, calcio, magnesio, sílice, zinc, sulfatos, fosfatos, cloruros).

- Aportan fibra, principalmente celulosa y pectinas.

- La mayoría tienen un alto contenido de agua que oscila entre un 80 y 95 por ciento.

\section{Conservación de Frutas y Hortalizas en Estado Fresco}

Las frutas y hortalizas siguen vivos aun después de la cosecha y al seguir respirando consumen oxígeno y liberan $\mathrm{CO}_{2}$, la vida comienza con la floración, el crecimiento, la maduración y concluye en la vejez y muerte AGL (2 001) y CEBAS (2008).

Los productos hortofrutícolas, tienen agua entre el 80 y 95\%, y por lo tanto están expuestos a pérdida de agua en sus tejidos AGL (2 001) y CEBAS (2 008).

Por transpiración implica la pérdida de peso vendible, apariencia y textura. Para controlar la humedad ambiental se utilizan recubrimientos y envolturas plásticas, control de la humedad en cámaras de almacenamiento $\mathrm{y}$ control de la velocidad de aire, el movimiento excesivo de aire favorece la deshidratación AGL( 2001) y CEBAS (2 008).

\subsection{Empacado de frutas al vacío}

El empacado de frutas al vacío es una de las tecnologías que se viene desarrollado por programas de conservación de frutas en Chile y Colombia para la prolongación de su vida útil; la generación de vacío se realiza con soluciones isotónica de glucosa correspondiente a los Brix de cada fruta. Giraldo G; Talens, Chiralt ( 2 004).

Las muestras se sometieron a pulsos de vacío de 10 minutos, con una presión de 50mbar; al final de la generación de vacío se restablece la presión atmosférica y se mantienen sumergidas en la solución durante tiempos determinados. (Germán A GIRALDO y Colaboradores 2006).

La impregnación a vacío es uno de los tratamientos que se les puede aplicar a las frutas para disminuir los niveles de $\mathrm{O}_{2}$, así como un medio para incorporar en la estructura antioxidante, conservante, azúcares y ácidos, que pueden mejorar las cualidades organolépticas (Giraldo GA. 2004).

La impregnación a vacío es uno de los tratamientos que se les puede aplicar a las frutas para disminuir los niveles de $\mathrm{O}_{2}$, así como un medio para incorporar en la estructura antioxidante, conservante, 
azúcares y ácidos, que pueden mejorar las cualidades organolépticas (Giraldo GA. 2004).

La generación de vacío causa una alteración estructural y fisiológica, ocasionada por el intercambio del gas presente en los poros por el líquido externo, lo que afecta los niveles requeridos en la respiración de frutas mínimamente procesadas $\mathrm{y}$, por tanto, influye en la vida útil de los productos. Giraldo GA. (2004).

El intercambio entre la fruta y las soluciones isotónicas ocurre al sumergir el producto en la fase líquida para someterlo a baja presión y así expandir el gas para que salga, y luego, al restituir la presión atmosférica, el producto se comprime favoreciendo la penetración del líquido exterior en los poros. Fito $\mathrm{P}$, Andrés A, Chiralt y, Pardo P. (1996).

Durante la generación de vacío las frutas presentaron diferencias significativas en ganancia de masa, pérdida de agua y ganancia de sólidos solubles, como respuesta a las diferencias en su porosidad y estructura y al mecanismo hidrodinámico, por los cambios de presión. Giraldo GA. (2 004).

Las frutas con mayor porosidad presentaron una mayor ganancia de solución durante el pulso a vacío. No obstante, la fracción volumétrica de líquido impregnado fue menor que el valor calculado a partir de la porosidad estimada, determinada mediante la ecuación: Barbosa y cols. (2000).

$$
x=\varepsilon\left(1-\frac{1}{r}\right)
$$

Donde:

$$
\begin{array}{ll}
\varepsilon & =\text { Porosidad } \\
\mathrm{r} & =\text { Medida representativa del solido } \\
\mathrm{X} & =\text { fracción volumétrica }
\end{array}
$$

Según Germán A GIRALDO G. frutas frescas e impregnadas a vacío (200 g de cada una) se introdujeron durante $2 \mathrm{~h}$ en una cámara hermética de 1,51 ; cada 5 minutos se determinó la concentración de gas de $\mathrm{CO}_{2}$ de la cámara mediante un analizador de gases (Agilent, M200). Para controlar la temperatura $\left(5\right.$ o $\left.10^{\circ} \mathrm{C}\right)$ se instaló la cámara dentro de una cabina con control de temperatura. Al graficar las lecturas de las concentraciones de $\mathrm{CO}_{2}$ frente al tiempo, se obtuvieron rectas, y a partir de la pendiente $(\alpha)$ se estimó el índice respiratorio mediante las ecuaciones:

$$
\begin{aligned}
& \mathrm{IR}=\frac{36000 \times \alpha \times \nabla}{\mathrm{M}} \\
& \alpha=\frac{\left[\left(\nabla_{i}\right)_{i}-\left(\nabla_{i}\right)_{0}\right] \times 100}{\mathrm{t}_{f}-\mathrm{t}_{0}}
\end{aligned}
$$

Donde:

IR: Indece respiratorio ( $\mathrm{ml} \mathrm{CO} / \mathrm{kg} \mathrm{h})$.

$\alpha$ : Pendiente debla variación de la fracción volumétrica en $\%$ de $\mathrm{CO}_{2}$ frente al tiempo (S)

$\nabla_{i}$ : Fracción volumétrica de $\mathrm{Co}_{2}$ con la muestra (1)

$\nabla:$ Volumen del espacio de cabeza de la camara (1) 
M: Masa de fruta $(\mathrm{kg})$

$\left(\mathrm{t}_{\mathrm{f}}-\mathrm{t}_{0}\right)$ : Intervalo de la respiración ( $\mathrm{s}$ ).

Se analizó el IR en relación al efecto causado por la IV y la temperatura.

\section{MATERIALES Y MÉTODOS}

\section{Lugar de Ejecución.}

El trabajo de investigación se realizó en la UNASAM - FIIA en el departamento de Ancash, provincia de Huaraz, en las instalaciones de los Laboratorios Especializados de la Facultad de Ingeniería de Industrias Alimentarias en los ambientes:

- Laboratorios especializados FIIA UNASAM

- Laboratorio de microbiología de alimentos

\section{MATERIALES}

\section{Materia prima e insumos}

\section{a. Materia prima}

Se usaron las frutas: manzana, durazno, mango, y fresas provenientes del Callejón de Huaylas recolectadas de los productores.

\section{b. Insumos.}

- Agua ozonificada.

- Agua tratada

- Empaque para frutas.

- Solución isotónica de glucosa

- Medio de cultivos para análisis microbiológico

- Medios de cultivos de análisis rápidos microbiológicos

- Policel comercial: Impermeable al vapor de agua y al oxigeno

116 Rev. Tayacaja 2(2): $110-128,2019$ ISSN:2617-9156
- Kilol

c. Equipos y Materiales

- Equipo de mínimo procesamiento Empacadoras al vacío

- Selladoras termo ajustables para envases Penetrómetro ADJJST$(\mathrm{Kg} / \mathrm{cm} 2)$

- Equipo de baño maría marca BIOTRON rango de medición 20 800 C- España.

- Estufa, marca MEMMERT - USA, rango de funcionamiento: $0-250^{\circ} \mathrm{C}$.

- Balanza analítica marca SARTORIUS, Capacidad: $160 \mathrm{~g}$ sensibilidad: $+0.0001 \mathrm{~g}$.

- Balanza comercial marca DELTA capacidad $20 \mathrm{Kg}$.

- Muestreador Automático modelo LC Series 200.

- Micro pipetas PERKN ELMER.

- Equipos de titulación.

- Campanas desecadoras.

- Refractómetro manual marca Kruss rango 1.333 a 1.520 .

- Termómetros rango $-20 \mathrm{a} 110^{\circ} \mathrm{C}$

- Cronómetro.

- Pie de rey.

- Potenciómetro, modelo 60 Marca TOLEDO rango de medición: 0 -14 acideziónica.

- Sacabocados de acero inoxidable.

- Morteros Pirex.

- Cocinas de gas.

- Mesa de proceso de acero inoxidable.

- Placas de Aw 
- Equipos de determinación

- Espátulas y utensilios estériles. Microbiológica:

- Incubadora.

- Horno esterilizador.

- Autoclave.

- Balanza mecánica.

- Mecheros de gas.

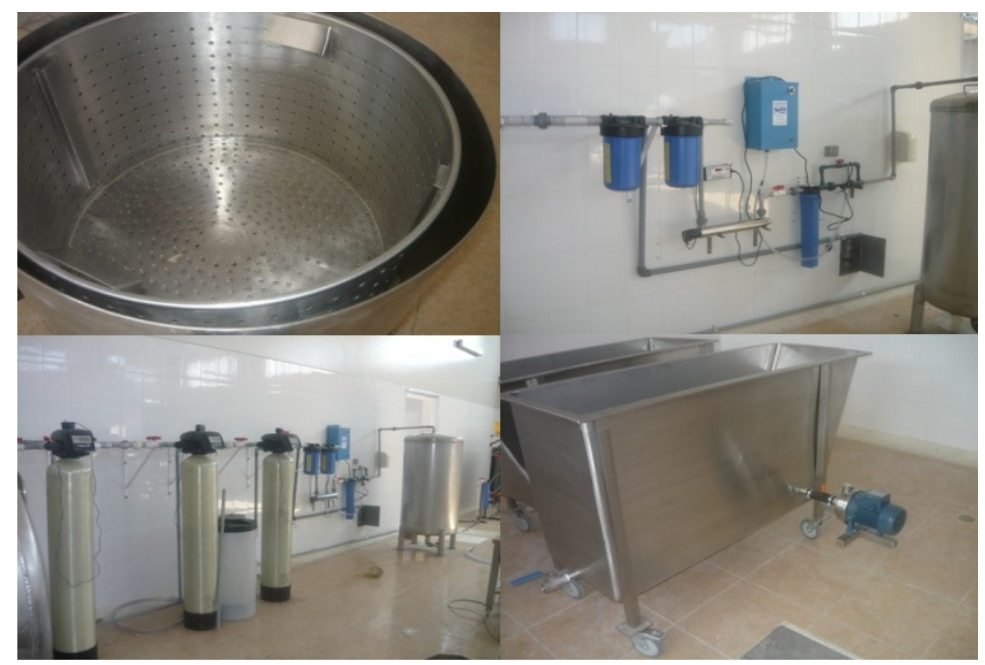

Figura 1. Equipo de ozonificación empleado en la investigación

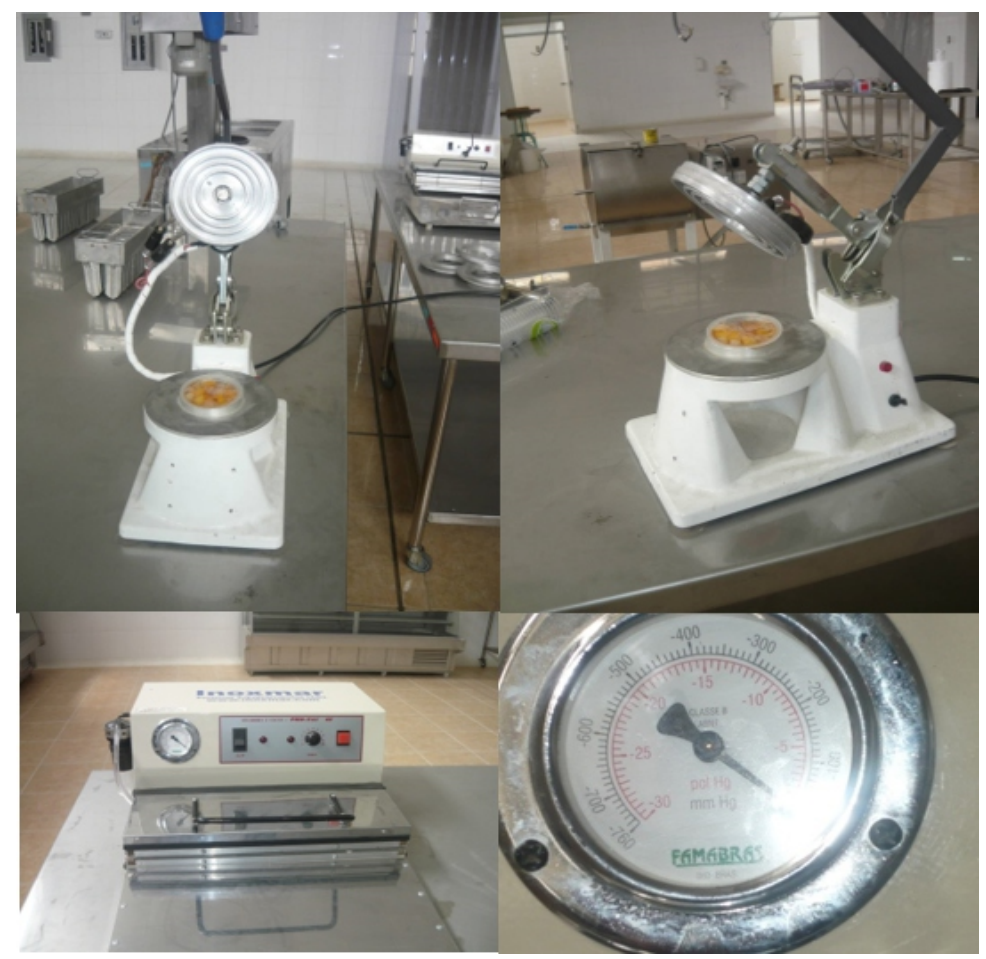

Figura 2. Equipo generador de pulsaciones de vacío y equipos empacador de fruta en soluciones isotónicas 


\section{Métodos de Análisis}

- Humedad El método a usarse será por desecación a la estufa según $\mathrm{A}$ OAC (1 999) basado en la pérdida de peso que sufre la muestra a los $105^{\circ} \mathrm{C}$ hasta obtener un peso constante.

- Sólidos Solubles: Método AOAC (1 999), lectura directa del refractómetro a $25^{\circ} \mathrm{C}$.

- pH: Método AOAC (1 999), uso de potenciómetro a temperatura ambiente.

\section{- Acidez Titulable: Método} recomendado por ITINTEC NORMA 203.105, (1 986)

- Textura: Método del Penetrómetro, recomendado por De Mant (1 976)

\section{Determinación Microbiológica}

Se realizará la preparación y dilución de frutas y hortalizas tratadas, según el recomendado por la ICMSF (2000), se evaluará los siguientes microorganismos.

- Recuento de mesófilos aerobios viables, según ICMSF (2 000) Método de recuento en placa.

- Determinación de coliformes fécales según ICMSF (2 000)

- Determinación de Hongos y levaduras, según JCMSF (2 000)

- Determinación de hongos y levaduras osmófilos Método de Howard.

\section{Metodología Experimental}

Los pasos a seguir para el estudio reportan las operaciones siguientes:

\section{Caracterización de la materia prima}

Recepción: De frutas y hortalizas serán recepcionadas y colocado en un ambiente fresco y seco a temperatura de refrigeración $5-10^{\circ} \mathrm{C}$.

Selección y limpieza: Mediante inspección visual se elimina los productos deteriorados.

Higienización con agua ozonificada: Las frutas y hortalizas se higienizarán con agua ozonificada.

Pelado y troceado de frutas: Los lotes de fruta se caracterizarán en grados Brix, y humedad en cubos. Se medirá la densidad aparente de las muestras mediante desplazamiento de volumen, por medio de picnometría, la masa se registrará antes y después de cada operación.

Impregnación al vacío: La generación de vacío se realizará con una solución isotónica de glucosa correspondiente a los Brix de cada fruta (manzana, durazno, mango y fresa). Las muestras se someterán a un pulso de vacío de 10 minutos, con una presión de 50mbar. Al final de la operación se restablecerá la presión atmosférica para mantener las muestras sumergidas en la solución durante: $05-10-15$ minutos.

Empacado: El empacado se realizará en empaques PET y bolsas de policel y laminados con sistema de atmósfera normal. 


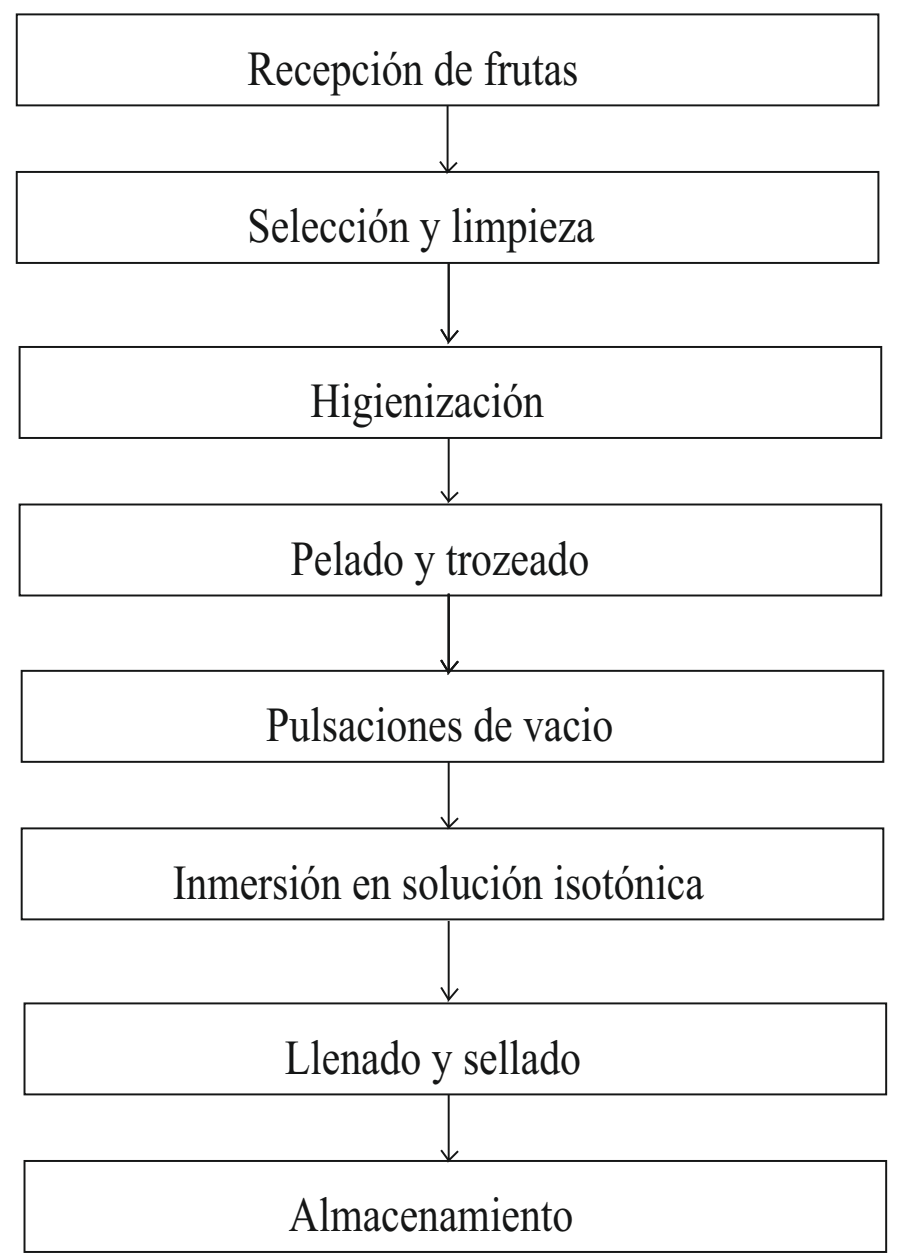

Figura 3. Diagrama de flujo para la obtención de frutas en trozos en soluciones isotónicas con pulsos de vacío.

\section{Evaluación sensorial}

Se empleo los tratamientos de datos obtenidos a las pruebas descriptivas según el método de Ureña - D arrigo, método aplicado al tratamiento de datos obtenidos a partir de pruebas descriptivas en la evaluación sensorial de alimento especialmente para la evaluación de texturas, cada atributo es evaluada por los jueces según la intensidad de la textura esto permite realizar una conversión de las respuesta de los jueces a a puntaciones que decrecen según se alejan de las otorgadas al producto ideal. Los valores asignados son los siguientes:

- Blando $=0.40$

- Semi Blando $=0.45$

- Firme $=0.50$

El valor de la suma de estos últimos, validado estadísticamente en un análisis de variancia (ANVA) para un diseño complemente al azar, será la calificación final con la que se determina en cuanto se asemeja el producto obtenido al patrón. 


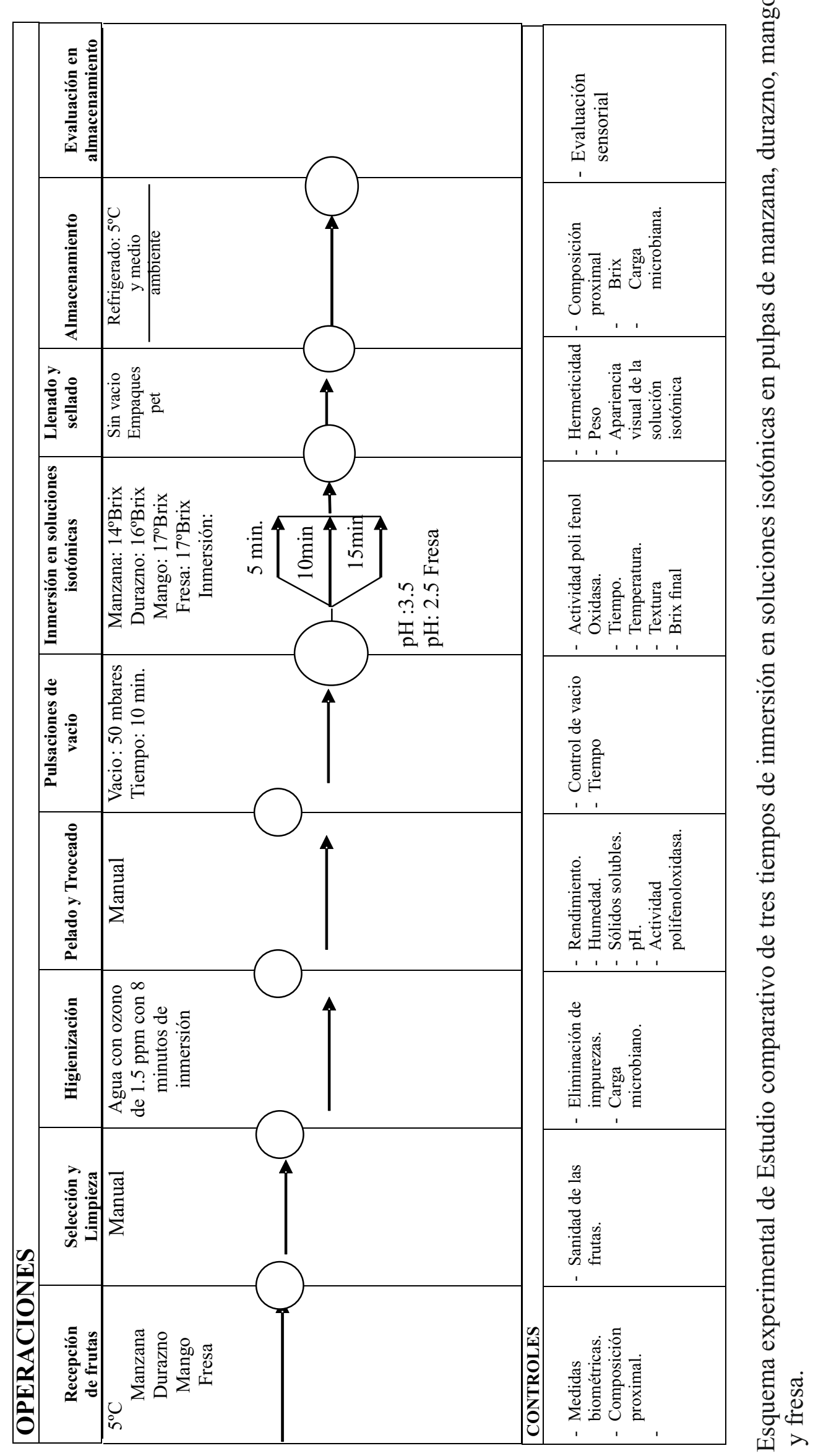


Figura 4: Esquema experimental de Estudio comparativo de tres tiempos de inmersión en soluciones isotónicas en pulpas de manzana, durazno, mango, y fresa.

\section{RESULTADOS}

Reporte de las medidas biométricas de frutas del estudio.

Tabla 1. Medidas biométricas de promedio de 100 frutas.

\begin{tabular}{lccccr}
\hline $\begin{array}{l}\text { Materia prima } \\
\text { Forma Biométrica }\end{array}$ & Diámetro $(\mathrm{cm})$ & Altura $(\mathrm{cm})$ & Peso $(\mathrm{g})$ & Densidad aparente $(\mathrm{Kg} / \mathrm{m})^{3}$ \\
\hline Manzana & 17,52 & 5,76 & 87,67 & 1049,955 & Esférica \\
Durazno* & 15,16 & 5,37 & 78,35 & 1132,769 & Esférica \\
Mango & 24,58 & 10,73 & 115,72 & 1368,786 & Cilíndrica \\
Fresa & 8,56 & 4,53 & 34,67 & 1016,352 & Esférica \\
\hline
\end{tabular}

*Variedad Blanquillo

Como se podrá observar de las tablas anteriores para los productos que muestran un contenido de humedad alto, su densidad aparente y global tiende la del agua, las formas Biométricas son las clásicas de los productos alimenticios indicados en los graficas de Hiesler.

\section{Composición proximal de las frutas.}

Tabla 2. Composición proximal de las frutas del estudio

\begin{tabular}{|c|c|c|c|c|c|c|c|}
\hline \multirow{2}{*}{$\begin{array}{l}\text { Materia prima } \\
\text { Sólidos solubles }\end{array}$} & \multicolumn{2}{|c|}{ Agua } & Proteína & & Carbohidratos & \multirow{2}{*}{$\begin{array}{l}\text { Fibra } \\
\qquad(\mathrm{g})\end{array}$} & Ceniza \\
\hline & (g) & (g) & $(g)$ & Grasa & (g) & & o \\
\hline Brix & & & & & & & \\
\hline Manzana & 83,65 & 0,257 & 0,47 & 15,22 & 0,95 & 0,33 & 13,56 \\
\hline Durazno & 86,48 & 0,768 & 0,10 & 16,78 & 0,72 & 0,70 & 16,23 \\
\hline Mango & 83,78 & 0,379 & 0,25 & 16,98 & 1,38 & 0,58 & 16,80 \\
\hline Fresa & 87,94 & 0,656 & 0,69 & 9,34 & 1,22 & 0,47 & 16,92 \\
\hline
\end{tabular}

\section{Resultados de la carga microbiana de las frutas antes de ser Higienizadas.}

En la Tabla 3 reporta la carga microbiana de las frutas y hortalizas antes de ser higienizadas.

Tabla 3. Resultado de análisis microbiológico de las frutas antes de ser Higienizadas.

Muestra Numeración de Microorganismos Numeración de Hongos y levaduras Aerobios mesófilos Osmófilos

\begin{tabular}{lcc} 
& $(\mathrm{ufc} / \mathrm{g})$ & $(\mathrm{ufc} / \mathrm{g})^{*}$ \\
\hline Manzana & $<1$ & 3 \\
Durazno & 2 & 4 \\
Mango & $1.0 \times 10^{1}$ & 4 \\
Fresa & $1.2 \times 10^{2}$ & 4 \\
\hline
\end{tabular}

* Máximo de campos positivos por cada 100 campos (método de Howard) 


\section{Higienización de frutas.}

Tabla 4: Resultados de higienización de frutas tratadas con agua ozonificada.

\begin{tabular}{cccc}
\hline FRUTA & $\begin{array}{c}\text { CONCENTRACION } \\
\text { DE OZONO } \\
(\mathbf{p p m})\end{array}$ & $\begin{array}{c}\text { TIEMPO DE } \\
\text { CONTACTO } \\
(\mathbf{m i n})\end{array}$ & $\begin{array}{c}\text { PRESENCIA DE } \\
\text { GERMENES } \\
\text { VIABLES }\end{array}$ \\
\hline Manzana & 1.5 & 8.0 & Ausentes \\
Durazno & 1.5 & 8.0 & Ausentes \\
Mango & 1.5 & 8.0 & Ausentes \\
Fresa & 1.5 & 8.0 & Ausentes \\
\hline
\end{tabular}

Caracterización de las pulpas mínimamente procesadas

Las frutas peladas y troceadas se caracterizaron después de ser sometidas a las técnicas de mínimo procesamiento las que se reportan en el Tabla 4.

Tabla 5. Caracterización de las pulpas antes de ser sometidas a las pulsaciones de vacío.

\begin{tabular}{lccccc}
\hline Pulpa de fruta & Porcentaje de Humedad & Grados Brix & $\mathrm{pH}$ & Temperatura $\left({ }^{\circ} \mathrm{C}\right)$ & $\begin{array}{l}\text { Actividad } \\
\text { polifenoloxidasa }\end{array}$ \\
\hline Manzana & 83,65 & 13,56 & 3,1 & 25 & Ausente \\
Durazno & 86,48 & 16,23 & 3,4 & 25 & Ausente \\
Mango & 83,78 & 16,80 & 3,8 & 25 & Ausente \\
Fresa & 87,94 & 16,92 & 2,8 & 25 & Ausente \\
\hline
\end{tabular}

\section{Inmersión en soluciones isotónicas}

Las pupas de frutas sometidas a pulsaciones de vacío en 50 mbares por un tiempo de $10 \mathrm{~min}$ sometidas a soluciones isotónicas.

Tabla 6. Respuesta de las pulpas de frutas a la inmersión de la inmersión isotónica de glucosa.

\begin{tabular}{lccllll}
\hline Pulpa de fruta & $\begin{array}{l}\text { Tiempo } \\
\text { (min.) }\end{array}$ & $\begin{array}{c}\text { Solución isotónica } \\
\text { de glucosa }\end{array}$ & $\begin{array}{c}\text { Actividad de } \\
\text { polifenoloxidasa }\end{array}$ & $\mathrm{pH}$ & Textura ${ }^{\circ}$ Brix final \\
\hline Manzana & 5 & $14^{\circ}$ Brix & Activa & 3.5 & Blanda & 12.7 \\
Manzana & 10 & $14^{\circ}$ Brix & Inactiva & 3.5 & Semi blanda & 13.3 \\
Manzana & 15 & $14^{\circ}$ Brix & Inactiva & 3.5 & Firme & 13.8 \\
Durazno & 5 & $16^{\circ}$ Brix & Inactiva & 3.5 & Semi blanda & 15.3 \\
Durazno & 10 & $16^{\circ}$ Brix & Inactiva & 3.5 & Semi blanda & 15.7 \\
Durazno & 15 & $16^{\circ}$ Brix & Inactiva & 3.5 & Firme & 15.8 \\
Mango & 5 & $17^{\circ}$ Brix & Inactiva & 3.5 & Semi blanda & 16.2 \\
Mango & 10 & $17^{\circ}$ Brix & Inactiva & 3.5 & Semi blanda & 16.6 \\
Mango & 15 & $17^{\circ}$ Brix & Inactiva & 3.5 & Firme & 16.9 \\
Fresa & 5 & $17^{\circ}$ Brix & Inactiva & 2.5 & Blanda & 16.4 \\
Fresa & 10 & $17^{\circ}$ Brix & Inactiva & 2.5 & Blanda & 16.9 \\
Fresa & 15 & $17^{\circ}$ Brix & Inactiva & 2.5 & Firme & 16.9 \\
\hline
\end{tabular}


Tabla 7. Resultados de los coeficientes de variabilidad para pulpas de frutas

\begin{tabular}{lcccc}
\hline $\begin{array}{l}\text { Pulpa de fruta en solución } \\
\text { Isotónica de Glucosa }\end{array}$ & $\begin{array}{c}\text { Textura } \\
\text { de la pulpa }\end{array}$ & $\begin{array}{c}\text { Varianza } \\
\left(\mathrm{S}^{2}\right)\end{array}$ & $\begin{array}{c}\text { Desviación estándar } \\
(\mathrm{S})\end{array}$ & $\begin{array}{c}\text { Coeficiente de variabilidad } \\
(\mathrm{C} . \mathrm{V})\end{array}$ \\
\hline Manzana & $\begin{array}{c}\text { Blanda } \\
\text { Demi Blanda } \\
\text { Firme } \\
\text { Blanda }\end{array}$ & $\mathbf{1 2 2} \mathbf{3 6 0 . 0 4}$ & $\mathbf{3 4 9 . 8 0}$ & $\mathbf{3 0 . 0 0}$ \\
Mango & $\begin{array}{c}\text { Semi Blanda } \\
\text { Firme } \\
\text { Blanda }\end{array}$ & $\mathbf{8 4 ~ 1 0 0 . 0 0}$ & $\mathbf{2 9 0 . 0 0}$ & $\mathbf{2 5 . 0 0}$ \\
Fresa & $\begin{array}{c}\text { Semi Blanda } \\
\text { Firme } \\
\text { Blanda }\end{array}$ & $\mathbf{1 0 6 5 8 9 . 1 9}$ & $\mathbf{3 2 6 . 4 8}$ & $\mathbf{2 8 . 0 0}$ \\
& $\begin{array}{c}\text { Semi Blanda } \\
\text { Firme }\end{array}$ & $\mathbf{1 6 6 5 4 5 . 6 1}$ & $\mathbf{4 0 8 . 1 0}$ & $\mathbf{3 5 . 0 0}$ \\
\hline
\end{tabular}

Solo para la pulpa de fresa el valor del coeficiente de variabilidad es heterogéneo.

\section{Resultados óptimos de pulpas frutas en el envasado en soluciones isotónicas}

Evaluado la respuesta de las pupas de frutas en pulsaciones de 50 mbares y $10 \mathrm{~min}$ se envasaron presentando las características indicadas en la tabla siguiente:

Tabla 8. Resultado de las pulpas envasadas en soluciones isotónicas selladas en empaques pet con un peso de 300 gramos

\begin{tabular}{lcrrlll}
\hline Pulpa de fruta & $\begin{array}{c}\text { Tiempo } \\
\text { (min.) }\end{array}$ & $\begin{array}{c}\text { Actividad de } \\
\text { polifenoloxidasa }\end{array}$ & $\mathrm{pH}$ & Textura ${ }^{\circ}$ Brix final & $\begin{array}{l}\text { Apariencia } \\
\text { de solución }\end{array}$ \\
\hline Manzana & 15 & Inactiva & 3.5 & Firme & 13.8 & No turbia \\
Durazno & 15 & Inactiva & 3.5 & Semi blanda & 15.8 & No turbia \\
Mango & 15 & Inactiva & 3.5 & Firme & 16.9 & No turbia \\
Fresa & 15 & Inactiva & 2.5 & Blanda & 16.9 & Turbia color rojiso \\
\hline
\end{tabular}

\section{Evaluación sensorial de la dureza de la pulpas}

Las pulpas de frutas envasadas en soluciones isotónicas se evaluaron bajo un perfil de dureza en 6 muestras con jueces no entrenados cuyo resultado se reportan en las tablas siguientes para un nivel de significación de $0.05(\alpha=0.05)$, se realizo un análisis de varianza para un diseño completamente Randomizado ya que las columnas son repeticiones.

Tabla 9. Calificación de cinco jueces no entrenados para la dureza de las pulpas de frutas envasadas.

\begin{tabular}{|c|c|c|c|c|c|}
\hline \multirow[t]{2}{*}{ Pulpa de fruta } & \multicolumn{5}{|c|}{ PANELISTA } \\
\hline & A & B & $\mathrm{C}$ & D & $\mathrm{E}$ \\
\hline Manzana & 0,40 & 0,50 & 0,40 & 0,40 & 0,50 \\
\hline Durazno & 0,50 & 0,50 & 0,50 & 0,50 & 0,50 \\
\hline Mango & 0,50 & 0,50 & 0,50 & 0,50 & 0,50 \\
\hline Fresa & 0,50 & 0,40 & 0,40 & 0,50 & 0,50 \\
\hline
\end{tabular}


Tabla10. Análisis de variancia $<$ ANVA $>$ para un diseño Randomizado.

\begin{tabular}{lccccc}
\hline Fuentes de variación & S.C. & G.L. & C.M. & Fcal & Ftab \\
\hline Entre tratamientos & 0,00200 & 4 & 0,00500 & 0,22057 & 2,78 \\
Error experimental & 0,05667 & 25 & 0,00227 & $(0,05)$ & \\
Total & 0,05867 & 29 & & & \\
\hline
\end{tabular}

Se concluye no hay diferencia entre los jueces ya que no hay evidencia estadística que las respuestas producidas por los jueces son similares en un nivel de significación de 0,05.

\section{Evaluación microbiológica}

La evaluación microbiológica de las frutas empacadas en envases de PET se relazó sobre gérmenes aerobios mesófilos, bacterias patógenas (coliformes) y hongos y levaduras osmófilos en periodos de $10-15-20-25$ días a temperatura ambiente como se indica siguiente

Tabla 11. Resultados de evaluación microbiológica de frutas empacadas.

\begin{tabular}{lcccc}
\hline $\begin{array}{l}\text { Frutas } \\
\text { empacadas }\end{array}$ & $\begin{array}{c}\text { Tiempo } \\
\text { (días) }\end{array}$ & $\begin{array}{c}\text { Numeración Aerobios } \\
\text { mesófilos } \\
\text { (ufc/g) }\end{array}$ & (ufc/g) & $\begin{array}{c}\text { Numeración de hongos } \\
\text { y levaduras osmófilos } \\
\text { (ufc/g) }\end{array}$ \\
\hline Manzana & 5 & ausente & ausente & 3 \\
Manzana & 15 & ausente & ausente & 3 \\
Manzana & 20 & ausente & ausente & 6 \\
Manzana & 25 & ausente & ausente & 15 \\
Durazno & 5 & ausente & ausente & 4 \\
Durazno & 15 & ausente & ausente & 4 \\
Durazno & 20 & ausente & ausente & 5 \\
Durazno & 25 & ausente & ausente & 9 \\
Mango & 5 & ausente & ausente & 4 \\
Mango & 15 & ausente & ausente & 5 \\
Mango & 20 & ausente & ausente & 9 \\
Mango & 25 & ausente & ausente & 18 \\
Fresa & 5 & ausente & ausente & 2 \\
Fresa & 15 & ausente & ausente & 4 \\
Fresa & 20 & ausente & ausente & 5 \\
Fresa & 25 & ausente & ausente & 5 \\
\hline
\end{tabular}

\section{DISCUSIÓN.}

Estas medidas están dentro del rango de las medidas indicadas por Calzada (1 978) y Alva (2 009).

Como se podrá observar de las tablas anteriores para los productos que muestran un contenido de humedad alto, su densidad aparente y global tiende a la del agua, como lo reporta Hayes G.D. ( 1 992). Las composiciones proximales indicadas en la tabla 2 son muy semejantes 
a la reportada por el Ministerio de salud y el instituto nacional de salud en la publicación Tabla de la composición de los alimentos peruanos. (2006) .

Al evaluar los resultados de las tablas del 3 al 4 se observó que los tratamientos que presentaron mayor concentración de ozono mayores de 1,5 ppm y mayor tiempo de contacto reducen drásticamente el contenido de patógenos y coliformes totales; y solo se reportaron presencias de gérmenes viables que fueron eliminados por el mayor tiempo de contacto del agua ozonificada, el tiempo de 8 minutos resulto un valor óptimo para la eliminación de los germines viables y los coliformes, estos valores coinciden con lo que afirma Kim et al. (1999).

Las características encontradas en la tabla 5 son similares a las reportadas Hayes G.D. (1992); estos valores permitirán la estandarización de las soluciones isotónicas de las pulpas después de ser sometidas a las pulsaciones de vacío y su posterior adición de soluciones isotónicas.

La tabla 6 muestra que los tiempos de pulsaciones da vacíos mayores a 10 minutos permite la eliminación eficiente del aire y del oxígeno dentro de las pulpas $\mathrm{y}$ estas al ser sometidas a soluciones isotónicas de glucosas logran un mejor equilibrio en los grados Brix final muy semejante a los grados Brix de las pulpas de frutas manteniendo una textura firme, esto es muy coincidente con lo que reporta Giraldo Germán (2 006). Siendo la fresa la única que enturbia la solución isotónica con un color rojizo por los pigmentos de esta fruta, presentando una apariencia poco agradable.

Las tablas 6 y 7 muestran los coeficientes de variabilidad que no es heterogénea para la pulpa de fresa lo que justifica por la presencia de pigmentos y una textura poco firme como lo indica Giraldo Germán (2006).

El reporte de las tablas 8,9 Y 10 indican que no hay diferencia significativa entre el resultado de los jueces con un grado de significación de 0.05 , sin embargo la pulpa de fresa es afectada por la migración de sus pigmentos hacia la solución isotónica dándole una apariencia indeseable al liquido de cubierta, como lo reportado por Giraldo Germán ( 2006 ).

La tabla 11 indica que solo las frutas con pulsaciones de 50 mbares en soluciones isotónicas de glucosa pueden durar hasta 20 días al medio ambiente ya que posterior a esa fecha la numeración de hongos y levaduras osmófilos superan el valor de 5 como lo indica la norma de ITINTEC 203.039 del año 1977 vigente.

\section{CONCLUSIONES}

Al término del estudio podemos establecer las conclusiones del trabajo de laboratorio que tendrán que acreditarse en la línea de mínimo procesamiento del laboratorio especializado de frutas y hortalizas: 
Es posible prolongar el tiempo de vida útil de las pulpas de frutas de manzana, durazno, mango y fresa con pulsaciones de $5 \mathrm{mBares}$ por 10 minutos en soluciones isotónicas de glucosa hasta 20 días a temperatura ambiente.

La higienización de la pulpa de frutas se logra con 1,5 ppm de ozono y un tiempo de contacto de 8 minutos.

La eliminación del aire en las pulpas de frutas se logra con $5 \mathrm{mBares}$ y un tiempo de 10 minutos permitiendo el ingreso de las soluciones isotónicas de glucosa en tiempos de contacto de 15 minutos.

La fresa pierde los pigmentos en las soluciones isotónicas dándole a la solución de cubierta una turbidez desagradable.

En la evaluación sensorial no hay evidencia estadística que las respuestas para la textura son similares en un nivel de significación de 0.05 .

A partir de los 20 días a temperatura ambiente se nota el crecimiento de Hongos y levaduras osmófilos con más de $6 \mathrm{ufc/g}$ sobrepasando el valor establecido por el ITENITEC.

\section{REFERENCIAS BIBLIOGRAFÍA}

Alzamora SM, Fito P, López-Malo A, Tapia S, Parada-Arias E, editores. Minimally processed fruits and vegetables, fundamental aspects and applications. Gaithersburg: Aspen 2000; 17:293-312. Disponible en: http://www. scielo.org.co/scieloOrg/php/reflink s.php?refpid $=$ S0121400420060002
$0000300009 \&$ pid=S 0121 40042006000200003\&lng=en

A.O.A.C. Association of Official Analytical Chemist Official Methods of Analysis. Washington 1980.Disponible en: http://www. scielo.org.co/scieloOrg/php/reflink s.php?refpid $=$ S0121-00420060 0020000300012\&pid $=$ S0121-4004 $2006000200003 \& \operatorname{lng}=$ en

Barat JM, Fito P, Chiralt A. Effect of osmotic solution concentration temperature and vacuum impregnation pre-treatment on osmotic dehydration kinetics of apple slices. Food science and technology international 2001;5(7):451-6. Disponible en: http://www.scielo.org.co/scieloOrg $/$ php/reflinks.php? refpid $=$ S0121$4004200600020000300001 \&$ pid $=$ S0121-40042006000200003\&lng= Baldwin E, Nísperos-Carriedo M, Baker R. Edible coatings for lightly processed fruits and vegetables. HortScience 1995;30(1):35- 3 . Disponible en:

http://www.scielo.org.co/scieloOrg/php/r efl inks.php? refpid=S 0121 $4004200600020000300017 \&$ pid $=$ S0121-40042006000200003\&lng= en

Barbosa G, Usha P, Palau E, Swanson B. Conservación no térmica de alimentos. Zaragoza: Acribia 2000.

Crisosto C, Mitcham E, Kader A. Recommendation for maintaining postharvest quality. California: 
2000.Diponible en:http://www .scielo. org.co/scieloOrg/php /reflinks.php?refpid=S 0121 4004200600020000300014\&pid= S $0121-40042006000200003$ $\& \operatorname{lng}=\mathrm{en}$

Cisneros-Zevallos L, Saltveit M, Krochta J. Hygroscopic coatings control surface white discoloration of peeled (minimally processed) carrots during storage. Journal of Food Science 1997;(62):363-3. D i s p o ible e n : http://www.scielo.org.co/scieloOrg $/$ php/reflinks.php?refpid $=$ S0 12140 04200600020000300016\&pid $=$ S0 121-40042006000200003\&lng=en

Giraldo GA. Conservación de frutas por un método combinado. Revista de Investigaciones 2004;1(14):121-8. Disponible en: http://www.scielo .org.co/scieloOrg/php/reflinks.php ?refpid $=$ S0121-40042006000200 $00300003 \&$ pid $=$ S0121-400420060 $00200003 \& \operatorname{lng}=\mathrm{en}$.

Giraldo G; Talens P, Chiralt A. Equilibrio osmótico del mango (Mangifera indica) en la deshidratación. Vitae 2004; 11(2):18-8.

Giraldo G, Duque A, Mejía C. La deshidratación osmótica como pretratamiento en la conservación de mora (Rubus glaucus) y uchuva (Physalis peruviana L.). Vitae 2005;12(1):15-7. Disponible en: http://www.scielo.org.co/scieloOrg /php/reflinks.php?refpid=S01214004200600020000300006\&pid
S0121-40042006000200003\& $\operatorname{lng}=\mathrm{e}$

Fonseca SC, Oliveira FRA, Brecht JK. Modelling respiration rate of fresh fruits and vegetables for modified atmosphere packages. A review. Journal of Food Engineering 2002;(52):99-20. Disponible en: http://www.scielo.org.co/scieloOrg $/$ php/reflinks.php?refpid=S01214004200600020000300008\&pid= S 0121-40042006000200003\& $\operatorname{lng}=\mathrm{en}$

Mitcham EJ, Crisosto $\mathrm{CH}$, Kader AA. Recommendation for maintaining postharvest quality. California: Department of Vegetable Crops, University of California 2000 . Disponible en: http://www.scielo.org.co/scieloOrg $/$ php/reflinks.php?refpid=S0121$4004200600020000300015 \&$ pid $=$ S $0121-40042006000200003$ $\& \operatorname{lng}=$ en

Salvador M., Jaime P, Oria R. Modelling of $\mathrm{O} 2$ and $\mathrm{CO} 2$ exchange dynamics in modified atmosphere packaging of Burlat cherries. Journal of Food Science 2002;62(1):231-4. Disponible en: http://www.scielo .org.co/scieloOrg/php/reflinks.php ?refpid $=$ S 0 121-40042006000 20000300010\& pid $=$ S0121-4004 $2006000200003 \& \operatorname{lng}=\mathrm{en}$

Watkins CB. Response of horticultural commodities to high carbon dioxide as related to modified atmosphere packaging. 
Hortechnology 2000;10(3):501-5.

Disponible en: http://www. scielo.org.co/scieloOrg/php/reflink s.php?refpid $=$ S0121-40042006000 $20000300011 \&$ pid=S 0121 $40042006000200003 \& \operatorname{lng}=\mathrm{en}$ Disponible en: http://www. scielo.org.co/scieloOrg/php/reflink s.php?refpid=S0121-4004200 $600020000300003 \&$ pid $=$ S0121$40042006000200003 \& \operatorname{lng}=$ en.

\section{CORRESPONDENCIA}

Mag. Ángel Quispe Talla

angelquispetalla@hotmail.com 